\title{
Correction: Al-Majid, A.M., et al., Tandem Aldol-Michael Reactions in Aqueous Diethylamine Medium: A Greener and Efficient Approach to Bis-Pyrimidine Derivatives.
}

\section{Int. J. Mol. Sci. 2013, 14, 23762-23773.}

Abdullah M. Al-Majid ${ }^{1}$, Assem Barakat ${ }^{1,2, *}$, Hany J. AL-Najjar ${ }^{1}$, Yahia N. Mabkhot ${ }^{1}$, Hazem A. Ghabbour ${ }^{3}$ and Hoong-Kun Fun ${ }^{3}$

1 Department of Chemistry, Faculty of Science, King Saud University, P.O. Box 2455,

Riyadh 11451, Saudi Arabia; E-Mails: amajid@ksu.edu.sa (A.M.A.-M.);

hany_33@hotmail.com (H.J.A.-N.); yahia@ksu.edu.sa (Y.N.M.)

2 Department of Chemistry, Faculty of Science, Alexandria University, P.O. Box 426-Ibrahimia, Alexandria 21321, Egypt

3 Department of Pharmaceutical Chemistry, Faculty of Pharmacy, King Saud University, P.O. Box 2457, Riyadh 11451, Saudi Arabia; E-Mails: ghabbourh@yahoo.com (H.A.G.); hfun.c@ksu.edu.sa (H.-K.F.)

* Author to whom correspondence should be addressed; E-Mail: ambarakat@ksu.edu.sa; Tel.: +966-1467-5884; Fax: +966-1467-5992.

Received: 25 April 2014 / Accepted: 25 April 2014 / Published: 30 April 2014

The authors wish to change Figure 2 in Section 2 of their paper published in IJMS [1]. Figure 2 is revised as follows. The authors and publisher apologize for any inconvenience.

Figure 2. ORTEP representation of the structure of $\mathbf{3 a}-\mathbf{c}$.

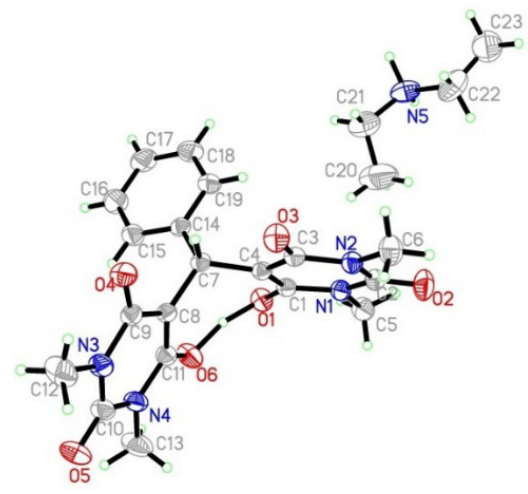

(a)

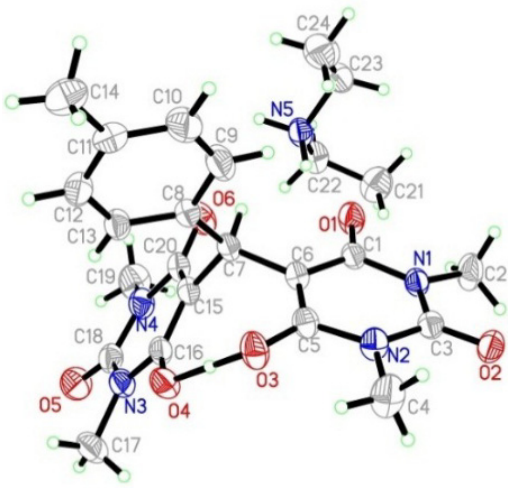

(b)

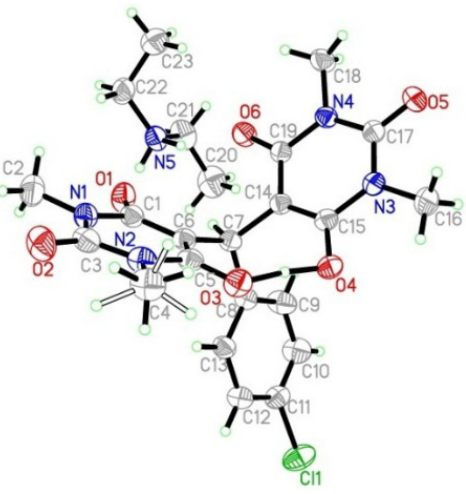

(c) 


\section{Reference}

1. Al-Majid, A.M.; Barakat, A.; Al-Najjar, H.J.; Mabkhot, Y.N.; Ghabbour, H.A.; Fun, H.-K. Tandem Aldol-Michael reactions in aqueous diethylamine medium: A greener and efficient approach to bis-pyrimidine derivatives. Int. J. Mol. Sci. 2013, 14, 23762-23773.

(C) 2014 by the authors; licensee MDPI, Basel, Switzerland. This article is an open access article distributed under the terms and conditions of the Creative Commons Attribution license (http://creativecommons.org/licenses/by/3.0/). 